\title{
CARDIAC AUTONOMIC NEUROPATHY IN DIABETES MELLITUS
}

\author{
Col AS KASTHURI", Surg Cdr RPS YADAV ${ }^{+}$ \\ (Armed Forces Medical College, Pune)
}

\begin{abstract}
Forty-eight out of 95 patients with diabetes mellitus, who were asymptomatic for autonomic nervous system affections, were evaluated with 3 bedside tests to detect subelinical cardiac neuropathy. There were 25 males and 23 females in the age range of $10-60$ years. The three tests carried out were, heart rate response to Valsalva manoeuvre, heart rate variation during deep breathing, and systolic blood pressure fall in response to standing. Of these 48 patients, $15(31.3 \%$ ) had evidence of neuropathy. Abnormality of the parasympathetic division was found in 13 patients and the remaining 2 patients had borderline affection. Three patients had evidence of a combined parasympathetic and sympathetic involvement. Sympathetic affection alone was not detected in any patient. Increased incidence was seen in older age group. Autonomic neuropathy was more common in patients who had the disease for over 5 years. There was no correlation with the sex of the patient or with metabolic control of diabetes.
\end{abstract}

MJAFI 1997; 53 : $7-10$

KEYWORDS : Autonomic nervous system diseases; Diabetes Mellitus; Neuropathy.

\section{Introduction}

D iabetic neuropathy involves both somatic and autonomic nerves. Though symptomatic cardiac autonomic neuropathy (CAN) occurs relatively infrequently 20 to 40 per cent of all diabetics have some impairment of cardiac autonomic nerve function [1]. The recent availability of sensitive, specific and reproducible non-invasive tests of autonomic function have enhanced our understanding of the prevalence, pathophysiology and clinical manifestations of this disorder [2]. Tests on symptomatic and asymptomatic patients show that parasympathetic innervation is affected first. These patients manifest resting tachycardia (due to decreased parasympathetic tone), orthostatic hypotension (due to decreased sympathetic activity) and decrease in exercise tolerance. They may also develop silent or painless myocardial infarction and sudden death $[3,4]$.

A combination of tests provide a sensitive measure of autonomic functions and have been used for evaluating patients with autonomic failure $[1,5]$. This work was undertaken to identify car- diac autonomic denervation in asymptomatic diabetic patients by utilizing 3 such bedside tests.

\section{Material and Methods}

Ninety-five patients with diabetes mellitus (DM) managed in a service hospital were studied. Diagnostic criteria for DM were as per WHO guidelines [6]. A detailed history-taking and clinical examination were carried out. History of symptoms suggestive of autonomic neuropathy (postural dizziness, sweating, anhydrosis, nocturnal diarthoea, and syncope) were enquired into. Presence of retinopathy was considered to be indicative of microangiopathy. Venous. blood samples, fasting and two hours postprandial (PP), were tested for sugar to grade glycemic control. Control was graded as either good (fasting less than 115 $\mathrm{mg} / \mathrm{dL}$ and 2 hours $\mathrm{PP}$ less than $140 \mathrm{mg} / \mathrm{dL}$ ), fair (fasting less than $140 \mathrm{mg} / \mathrm{dL}$ and 2 hours PP less than $200 \mathrm{mg} / \mathrm{dL}$ ) or poor (fasting more than 140 $\mathrm{mg} / \mathrm{dL}$ and 2 hours PP more than $200 \mathrm{mg} / \mathrm{dL}$ ) [7].

Forty-seven patients who had symptoms of autonomic neuropathy were excluded. The remaining 48 patients underwent 3 tests to detect subclinical autonomic neuropathy. The tests were,

Assoc Prof (Medicine), Amed Forces Medical College, Pune 411040; ${ }^{+}$Classified Specialist (Medicine), INHS Kasturi, Lonavala. 
heart rate response to Valsalva manoeuvre (Test No 1), heart rate variation during deep breathing (Test No 2), and blood pressure response to standing (Test No 3). The first two tests assess parasympathetic and the third test assesses sympathetic integrity [2]. Thirty, age and sex matched, healthy volunteers were also subjected to these 3 tests.

Test No 1: Heart rate was recorded for 1 minute after 15 minutes of rest in a quiet room. Then the patient blew into an aneroid blood pressure (BP) apparatus to maintain the pressure at $40 \mathrm{mmHg}$ for 15 seconds. ECG was recorded during this period and for another minute after it. Valsalva ratio was derived by dividing maximum $R-R$ interval by the minimum R-R interval. Ratio of 1.21 and above were taken as normal, 1.10 and below as abnormal, and 1.11 to 1.20 as borderline.

Test No 2: Baseline ECG was recorded after 10 minutes of bed rest. Patient then took 6 deep breaths with no pause in between. The difference between the maximum (fastest) heart rate during inspiration and the minimum (slowest) heart rate during expiration was calculated. A difference of 15 or more beats per minute was taken as normal, 10 or less beats as abnormal and 11 to 14 beats as borderline.

Test No 3: Systolic BP was recorded in the supine posture and then in the standing posture. $A$ fall of $10 \mathrm{mmHg}$ or less in the standing posture was taken as normal, 11 to $29 \mathrm{mmHg}$ as borderline and $30 \mathrm{mmHg}$ or more as abnormal.

Parasympathetic neuropathy was considered to be present when test No 1 and 2 were found abnormal. They were then correlated with age, metabolic control, duration of DM and microangiopathy. No differentiation was made between insulin dependent diabetes mellitus (IDDM) and non-insulin dependent diabetes Mellitus (NIDDM).

\section{Results}

Of the 95 patients studied, 48 ( 25 males and 23 females, age range 10-60 years) patients had no symptoms of autonomic dysfunction. Age distribution of patients is given in Table 1. Results of the tests of autonomic function are given in Table 2. Thirteen patients had both Test 1 \& 2 abnormal and were diagnosed as having parasympathetic denervation. In 2 patients both Test $1 \& 2$ gave borderline results. Of the thirteen patients with abnormal results 3 also had sympathetic denervation (abnormal Test 3). Autonomic neuropathy was detected in all the 3 patients with proliferative retinopathy, in 9 out of 19 patients (47.4\%) with nonproliferative retinopathy and in 3 out of 26 patients (11.5\%) with no retinopathy. Relation of cardiac autonomic neuropathy to duration of disease has been shown in Table 3 . Its incidence increases with the duration of disease. Presence of neuropathy in various grades of control of diabetes is shown in Table 4. No correlation was found between grades of control and presence of autonomic neuropathy. None of the 30 control subjects showed any abnormality suggestive of DM or CAN.

TABLE 1

Results of sutonomic tests in $\mathbf{4 8}$ patients with diabetes mellitus

\begin{tabular}{lrcc}
\hline & Normal & Borderline & Abnormal \\
\hline Test 1 & 33 & 2 & 13 \\
Test 2 & 26 & 9 & 13 \\
Test 3 & 36 & 9 & 3 \\
\hline
\end{tabular}

TABLE 2

Age distribution of 48 patients with cardiac autonomic neuropathy

\begin{tabular}{lccc}
\hline Age (yrs) & Total & $\begin{array}{c}\text { Diabetes } \\
\text { denervation }\end{array}$ & $\begin{array}{c}\text { with \% of } \\
\text { patients with } \\
\text { neuropathy }\end{array}$ \\
\hline $10-19$ & 8 & 0 & 0 \\
$20-29$ & 7 & 1 & 14.3 \\
$30-39$ & 9 & 2 & 22.2 \\
$40-49$ & 11 & 2 & 18.2 \\
$50-59$ & 6 & 4 & 66.7 \\
$60-69$ & 7 & 6 & 85.7 \\
\hline Total & 48 & 15 & 31.3 \\
\hline
\end{tabular}

\section{Discussion}

Complications of diabetes mellitus continue to account for increased morbidity and mortality. Measurement of peripheral and autonomic nerve functions in diabetic patients help in establishment of prospective natural history, its pathogenesis and predict the beneficial effects of various drugs [5]. 
TABLE 3

Duration of disease and cardiac autonomic neuropathy (CAN)

\begin{tabular}{lccc}
\hline Duration (months) & Total & With CAN & Percentage \\
\hline $0-12$ & 7 & 1 & 14.3 \\
$13-24$ & 2 & 0 & - \\
$25-36$ & 3 & 1 & 33.3 \\
$37-60$ & 4 & 1 & 25.0 \\
$61-120$ & 14 & 4 & 28.6 \\
$>120$ & 18 & 8 & 44.4 \\
\hline Total & 48 & 15 & 31.3 \\
\hline
\end{tabular}

TABLE 4

Grades of metabolic control and cardiac neuropathy

\begin{tabular}{lrcc}
\hline Grades of controi & Total & $\begin{array}{c}\text { With } \\
\text { neuropathy }\end{array}$ & Percentage \\
\hline Good & 28 & 9 & 32.1 \\
Fair & 4 & 1 & 25.0 \\
Poor & 16 & 5 & 31.3 \\
\hline Total & 48 & 15 & 31.3 \\
\hline
\end{tabular}

Prevalence of autonomic neuropathy in diabetes varies from 7 per cent in patients with no peripheral neuropathy to 80 per cent in those with peripheral neuropathy and symptoms of autonomic neuropathy [1]. Measurable autonomic neuropathy occurs in 17 to 60 per cent of cases [3]. In this study, 49.5 per cent (47 patients) had autonomic symptoms. Out of the remaining 48 asymptomatic patients $15(31.3 \%)$ were diagnosed to have CAN on the basis of the 3 tests employed. Parasympathetic involvement was the commonest type $(22.9 \%)$ followed by combined parasympathetic and sympathetic involvement. The sympathetic division alone was not involved in any of our patients. These observations are similar to those of other studies [1,8-1I].

Abnormalities of autonomic function increase progressively with age. In this study, this was observed in 14.3 per cent of cases in the 3rd decade which increased to 85.7 per cent in the 7 th decade. This is probably related to the increased incidence of disease per se with age and to the duration of DM. As no comparison was made between IDDM (which occurs in younger age group) and NIDDM patients, no comments can be offered on the rela- tion of autonomic neuropathy to the type of DM. Various follow-up studies have shown that incidence of autonomic neuropathy may or may not increase with duration of disease $[1,10]$. In the present study, incidence was found to increase with duration of disease. No comments can be offered in relation to sex as this study included only a select population.

Better metabolic control improves the results of neurological tests [10]. However, no association between grades of control and incidence of neuropathy was observed in this study. Incidence of neuropathy was more in patients with significant retinopathy which was similar to the observation reported in other studies [8]. Myocardial infarction, cardiac arrest and sudden death may result as a complication of diabetic cardiac denervation $[1,3,10]$.

The 3 bedside tests used in this study are easy to perform, reproducible and other studies have confirmed their clinical validity. A combination of tests have been recommended to avoid reliance on a single measure of autonomic function $[9,11]$. Other more specialized techniques, which are difficult to perform, include spectral analysis of heart rate, measures of baroreceptor function, long-term cardiac monitoring and measures of cardiovascular responses to pharmacological agents $[5,8]$.

Almost one half of our patients had autonomic symptoms as assessed by simple bedside tests. More specialized tests available at present are difficult to perform, hence these bedside tests are still useful. Vagal cardiac neuropathy was the commonest type. Correlation was found between retinopathy arid neuropathy. No correlation was found between sex and grades of diabetes control. Increased incidence was detected in higher age group with longer duration of disease. Large multicentric trials are required to assess their longterm effects.

\section{REFERENCES}

1. Gwilt DJ, Pentecoast BL. The heart in diabetes. In: Nattras $\mathbf{M}$, editor. Recent advances in diabetes. Vol 2. Edinburgh: Churchill Livingstone 1986; 177-94.

2. Ewing DJ, Clarke BF. Diabetic autonomic neuropathy: present insights and future prospects. Diabetes Care 1986; 9: 648-65.

3. Bays HE, Pfeifer NA. Peripheral diabetic neusopathy. Med Clin North Am 1988; 6: 1439-64. 
4. Stribling D, Perkins CM. Aldose reductase inhibitors. In: Nattras $M$, editor. Recent advances in diabetes. Vol 2. Edinburgh: Churchill Livingstone 1986; 169-76.

5. McLeod JG, Tuck RR. Disorders of the autonomic nervous system, Part 2. Investigations and treatment. Ann Neurol 1987; 21: 519-29.

6. Diabetes mellitus. WHO Technical report Series 727. Geneva: WHO 1985; $10-2$.

7. Nesto RW, Zarich SW, Jcoby RM, Kamalesh M. Heart disease in diabetes. In: Kahn CR, Weir GC, editors. Joslin's Diabetes mellitus. 13th ed. Philadelphia: Lea \& Febiger 1994; 508 and 836-51.
8. Tarsy $D$, Freeman $R$. The nervous system and diabetes. In: Kahn CR, Weir GC, editors. Joslin's Diabetes mellitus. 13th ed. Philadelphia: Lea \& Febiger 1994; 794-816.

9. Nijhawan S, Mathur A, Singh V, Bhandari VM. Autonomic and peripheral neuropathy in insulin dependent diabetics. J Assoc Physicians India 1993; 41: 565-6.

10. Shah SN, Shah SJ. Autonomic nervous system - not forgotten. J Assoc Physicians India 1994; 42: 7-8.

11. Olson OC. Diabetic neuropathy : Diagnosis and management of Diabetes mellitus. 2nd ed. New York: Raven Press 1988; 215-26. 